\title{
Non-Polio Enteroviruses, the Neglected and Emerging Human Pathogens: Are we Waiting for the Sizzling Enterovirus Volcano to Erupt?
}

\author{
C DURGA RAO* \\ Department of Microbiology \& Cell Biology, Indian Institute of Science, Bangalore 560 012, India
}

(Received on 4 May 2014; Revised on 19 December 2014; Accepted on 23 December 2014)

\begin{abstract}
Enteroviruses consist of a large group of pathogenic viruses, poliovirus being the notorious member. For the last several decades, all the attention and resources were directed towards control and eradication of poliomyelitis in India. There is very little research on non-polio enteroviruses (NPEVs), the cousins of poliovirus, which are associated with a wide range of diseases, especially in infants and young children. We have established an active research group on NPEVs during the last six years and showed that about $35 \%$ of non-polio acute flaccid paralysis (NP-AFP) children were positive for NPEV infections, and detected 66 serotypes in NP-AFP children, EV71 being more frequently detected followed by Echovirus 13 and CVB5. Long-term comparative epidemiological studies on NPEVs and rotavirus in acute diarrhoea revealed for the first time, that, NPEV association is as significant as that of rotavirus. A surprising observation was the contrasting seasonal prevalence between enterovus- and rotavirus-associated diarrhoea, the former predominating in non-winter months and the latter occurring primarily in the winter season. NPEVs were associated with epidemics-like outbreaks during which they were detected in up to $50 \%$ children with acute diarrhoea. In recent years, enterovirus has been identified to be associated with acute encephalitis cases in Uttar Pradesh. HFMD outbreaks have been reported in recent years, including a major outbreak in Bangalore in 2013. Since, no studies exist in India on the biology of EVs, including HFMD, we have recently initiated work on this emerging disease. Our studies uncover an urgent need for detailed studies on these "so far" neglected and emerging viruses for effective child health management in the country.
\end{abstract}

Key Words: Enterovirus; Poliovirus; Coxsackievirus; Echovirus; Diarrhoea; Hand-foot-and-Mouth Disease; Acute Flaccid Paralysis; Rotavirus

\section{Introduction}

The family Picornaviridae currently consists of 15 genera, being expanded continuously, of which the genus enterovirus represents the largest, containing about 200 serotypes (Picornavirus Home 2014). Enterovirus genus contains at least 10 species, the major human pathogenic species being; human enterovirus A-D, and human rhinovirus A-C, representing Coxsackiecirus A and B (CVA and CVB), Echovirus (E), Poliovirus, relatively newer enteroviruses $(\mathrm{EV})$ and rhinovirus (Picornavirus
Home 2014). Human enteroviruses are common and are associated with a wide spectrum of diseases, infecting more than a billion people worldwide each year. Majority of the enterovirus infections are considered to be asymptomatic, with less than $1 \%$ of them resulting in severe disease leading to high mortality, especially in infants and young children (Pallansch and Roos, 2007). The spectrum of diseases associated with enterovirus infections in humans include; acute flaccid paralysis (AFP), aseptic meningitis, acute encephalitis, type-1-diabetes, uveitis, hand, foot and mouth disease (HFMD),

*Author for Correspondence: E-mail: cdr@mcbl.iisc.ernet.in; Tel: 080-23602149 
diarrhoea, brainstem disease, herpangina, exanthema, pleurodynia, cardiomyopathy, coagulopathy, atherosclerotic arterial disease, multi-system hemorrhagic disease, sudden deftness, fatal illness with pulmonary hypertension in neonates, transverse myelitis, aplastic anemia etc. (Pallansch and Roos, 2007; Chen and Shih, 2011; Avellon et al., 2003; De et al., 2011; Lewthwaite et al., 2010; el-Sageyer et al., 1998; Hinkkanen 2003; Lashkevich et al., 2004; Lee et al., 2009; Lin et al., 2003; Moldin 1980; Moldin, 1986; Mostoufizadeh et al., 1983; Ooi et al., 2010; Ortner et al., 2009; Rao et al., 2012; Rao et al., 2013; Reyes et al., 1983; Soloman and Willson 2003; Lukashev et al., 2003; Centres for Disease Control and Prevention 2003).

Enterovirus genome consists of 7.4-7.5 kb-long single-stranded positive-sense RNA, which is covalently linked to the viral polypeptide $3 \mathrm{~B}$, referred to as $\mathrm{VPg}$, at the 5' end, polyadenylated at the 3' end, and contains a long Open Reading Frame (ORF), encoding a single polyprotein. Upon infection, the genomic RNA directly serves as template for the synthesis of the polyprotein, which is subsequently cleaved into four structural and seven non-structural proteins including VPg. Two proteases 2A and 3C, encoded by the viral genome, cleave the polyprotein into individual polypeptides (Fig. 1). The four structural proteins VP1-VP4 form the viral capsid, VP1 being the major capsid protein and serotypespecifying antigen. Majority of the studies on enteroviruses were focussed on poliovirus because of its association with severe lifelong paralytic disease in infants and children. In this review, I refer all enteroviruses, other than poliovirus as non-polio enteroviruses (NPEVs).

India has made a remarkable progress in eradication of wild poliovirus transmission, and very recently, it has been declared a polio-free nation. In spite of the success of polio eradication, an alarmingly large number of non-polio-AFP (NP-AFP) cases are being reported annually, the number increasing each year (Fig. 2A) (Rao et al., 2012). Though NPEVs are a major cause of AFP, detailed knowledge is lacking on the spectrum of serotypes associated with NP-AFP and other enteroviral diseases in India. Further, though enteroviruses are common, and majority of them are transmitted through fecal-oral route and first replicate in the cells of intestinal tissues prior to affecting the target organs, their role in diarrhoea has neither been studied in detail nor established. Hence majority of the epidemiological studies on diarrhoea failed to include NPEVs in their investigations. Further, the causative agents in about $30-40 \%$ of diarrheal cases are yet to be identified

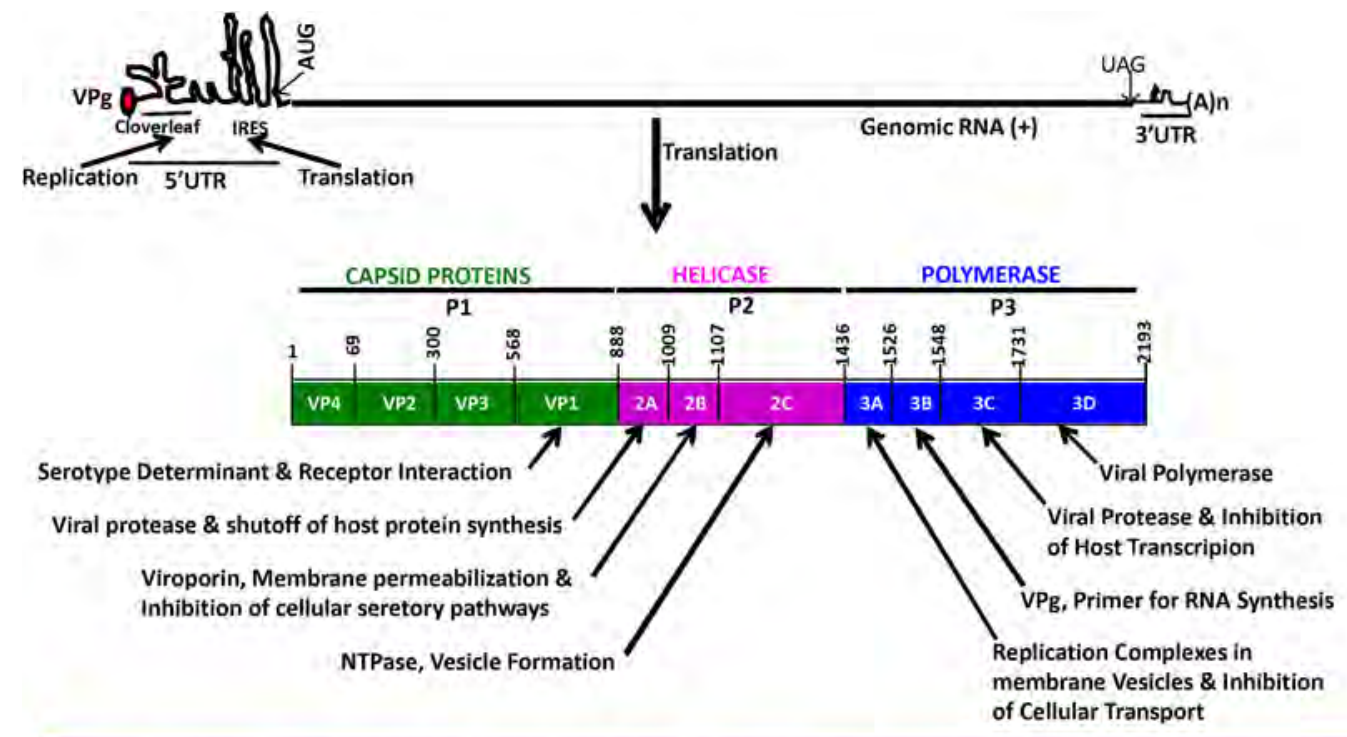

Enterovirus GenomeOrganization, Polyprotein Products and their Functions

Fig. 1: Structural organization of enterovirus genomic RNA, its encoded proteins and their functions 
(Denno et al., 2007; Greniger et al., 2009; Holtz et al., 2008; Holtz et al., 2009).

Although enteroviruses are associated with many diseases in humans, the actual incidence of their infections in children worldwide is yet to be determined. Research on these viruses clinical, epidemiological, fundamental and translational, is almost lacking in the country. The major effort in this country, supported by World Health Organization (WHO), during the last three decades has been eradication of wild poliovirus transmission. We have initiated studies on NPEVs six years ago to understand their association with NP-AFP, acute diarrhoea and persistent diarrhoea, the spectrum of their antigenic diversity associated with these diseases, and molecular mechanisms underlying enterovirus pathogenesis. During 2013, a major outbreak of HFMD occurred in Bangalore for the first time, several thousand children having been affected (Times of India, 2013). But we do not have any research activity on these important pathogenic viruses in the country. To understand the antigenic diversity of the NPEVs associated with HFMD and vaccine development, we have recently initiated work on the pathogens associated with the disease.

Our studies revealed for the first time, that, NPEVs association with acute diarrhoea is as significant as rotavirus. This review summarises the results of our long-term studies on NPEVs, their association with NP-AFP and acute diarrhoea and their genetic diversity compared to the strains isolated in other countries.

\section{Non-Polio Enteroviruses in NP-AFP}

\section{Background}

Acute flaccid paralysis constitutes sudden onset of weakness and floppiness in any part of the body of a child less than 15 years of age, or paralysis in any person with suspected poliovirus infection (Field Guide, 2005). It is a complex and broad clinical syndrome and may be associated with a wide range of microbial and non-microbial agents and immunological processes. To maximize the chances of detection of every suspected case of poliomyelitis, the Global Poliomyelitis Eradication Initiative (GPEI), in 2005, expanded the case definition of AFP to include all possible causes of non-polio AFP (NPAFP), including Guillian-Barre syndrome, transverse myelitis, traumatic neuritis and ambiguous cases (Field Guide, 2005). With the launch of GPEI in 1988 for effective vaccination, surveillance and monitoring of wild poliovirus transmission, the number of wild polio AFP cases remarkably declined from about 350,000 to 974 globally in 2010 (Centres for Disease Control and Prevention, 2010). With the introduction of effective polio vaccination programmes in India, poliomyelitis cases came down dramatically from about 35,000 cases each during 1994 and 1995 to 42 in 2010 (Centres for Disease Control and Prevention, 2010; Global Polio Eradication Initiative [GPEI] 2011; National Polio Surveillance Project [NPSP] 2014). South East Asian Region (SEAR) has been declared polio-free in March 2014, India being the last country becoming polio-free amongst the SEAR group of countries.

Concomitant with the decline in wild poliovirus transmission, a steady and steep increase in the number of NP-AFP cases from about 8000-9700 during the period $1998-2003$ to 55000 to $>60000$ cases from 2010 to date (Fig. 2A) (Global Polio Eradication Initiative 2011); National Polio Surveillance Project 2014) was observed. This large increase in NP-AFP cases, representing AFP cases caused by agents other than poliovirus, probably reflects the efficient implementation of the expanded definition of AFP, and use of highly sensitive detection and surveillance methods by NPSP in India from 2005 onwards, in comparison to other polioendemic countries Afghanistan, Nigeria and Pakistan. The annualized AFP rate also remarkably increased from about 1.5-2.0 per 100,000 children during 19982003 to 12.0-16.0 from 2004 onwards (Fig. 2B) (Global Polio Eradication Initiative 2011).

In spite of the alarming incidence of NP-AFP in the country, prior to our studies, there are no detailed studies to understand the causes of NP-AFP in India. A few studies in India and Pakistan have identified about 6-12 serotypes in AFP samples, using methods that have limited scope in identifying the 

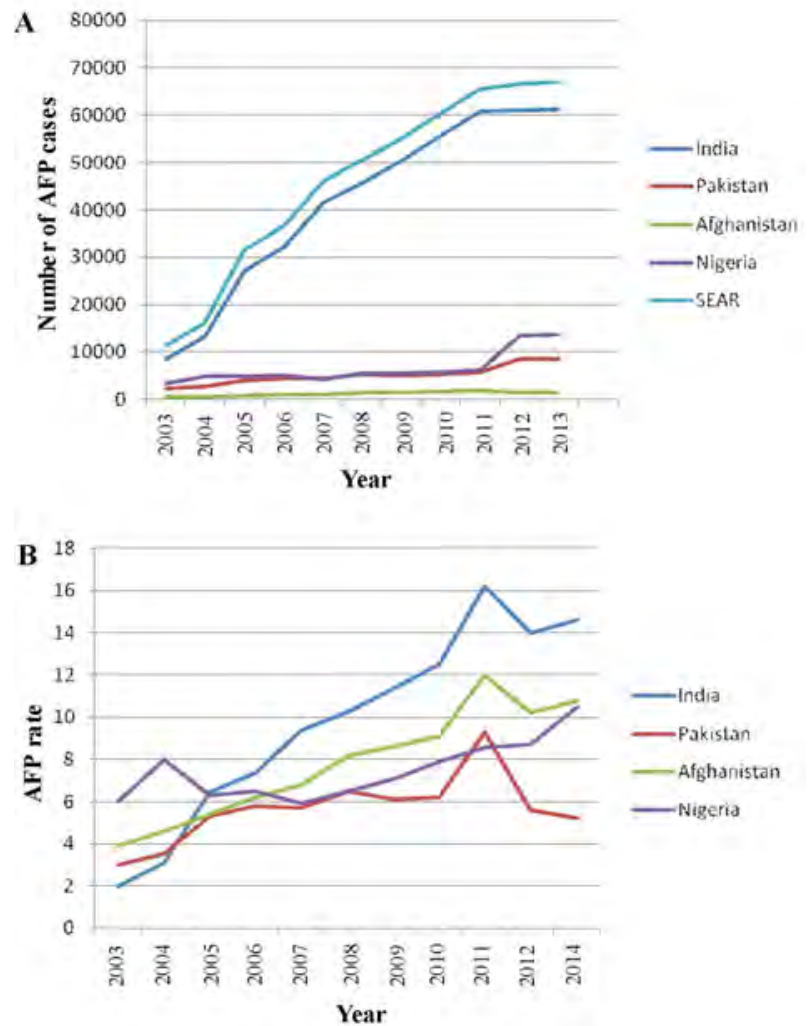

Fig. 2: Year-wise increasing number of AFP cases (A), and annualized AFP rate $(B)$ in India in comparison to other polio-endemic countries from 2003 to 2013

large repertoire of NPEV serotypes. Although NPEVs are known to be associated with NP-AFP (Ortner et al., 2009; Persu et al., 2009; Bingjun et al., 2008), detailed knowledge on antigenic diversity of these viruses in India is still lacking. In order to understand the spectrum of NPEV serotypes associated with NPAFP, we have developed a relatively simple RT-PCR protocol using just a pair of degenerate primers, which could amplify VP1 gene from a large number of cell culture-positive isolates, as well as, clinical samples and, were better than the multiple sets of primers used in previous studies in other countries (Oberste et al., 2000). However, some coxsackievirus A and EV71 isolates could not be amplified efficiently with these primers, and EV71 strains were amplified using serotype-specific primers (Rao et al., 2012).

\section{Extreme Antigenic Diversity of NPEVs Associated with NP-AFP}

Of 2786 stool specimens from independent AFP cases, collected from the previously polio-endemic state of Uttar Pradesh and two polio-free southern states of Karnataka and Kerala, $823(\sim 30 \%)$ were positive for NPEV growth in Rhabdomyosarcoma cells. However, the VP1 gene from only about 70\% of the isolates could be amplified using our primers. The non-typeable isolates also failed to be amplified by primers used in other studies (Oberste et al., 2000), suggesting genetic diversity among Indian NPEVs. It may be noted, that due to lack of sequence data from Indian NPEVs, the primers for RT-PCR were designed based on sequences of prototype strains isolated in other countries. We have also examined 780 stool samples from apparently healthy children, which showed about $3 \%$ of the samples to be positive for NPEVs. Interestingly, while only about $0.9 \%$ of the samples from healthy children collected in winter months were positive for NPEVs, about $5.0 \%$ of the samples collected in other seasons were NPEV positive (Rao et al., 2012).

Indian NPEVs in NP-AFP patients exhibited extreme antigenic diversity. We have identified 66 serotypes, by far, the largest number of types identified in a single epidemiological study on NPAFP (Fig. 3). A few studies in India and Pakistan identified only 6-12 serotypes (Dhole et al., 2009; Saeed et al., 2007). Among the 66 serotypes, nine serotypes were more prevalent than others, with EV71 (8.4\%) being more frequently detected followed by E13 (7.1\%), CVB5 (5.0\%) and E6, E7, E11, E14, E19 and E33, representing 3.3\%-4.5\% of the isolates. Only 15 serotypes CVA4, CVB2, CVB4, E6, E7, E13, E14, E17, E19, E25, E30, E33, EV71, EV75 and EV80 were detected in all the three states. Forty-eight serotypes, including CVB5, were not detected in Kerala, reflecting the relatively small number of samples available from that state. Some CVA strains poorly replicate or do not at all replicate in RD cells as evident from the observation that 4 stool samples negative for NPEV in RD cells were positive for CVA4 and CVA8 by RT-PCR. Following our report, a recent study also reported similar number of serotypes from Western part of India (Laxmivandana et al., 2013). A recent study also observed genetic diversity in echovirus 13 strains in India (Mann et al., 2013). 


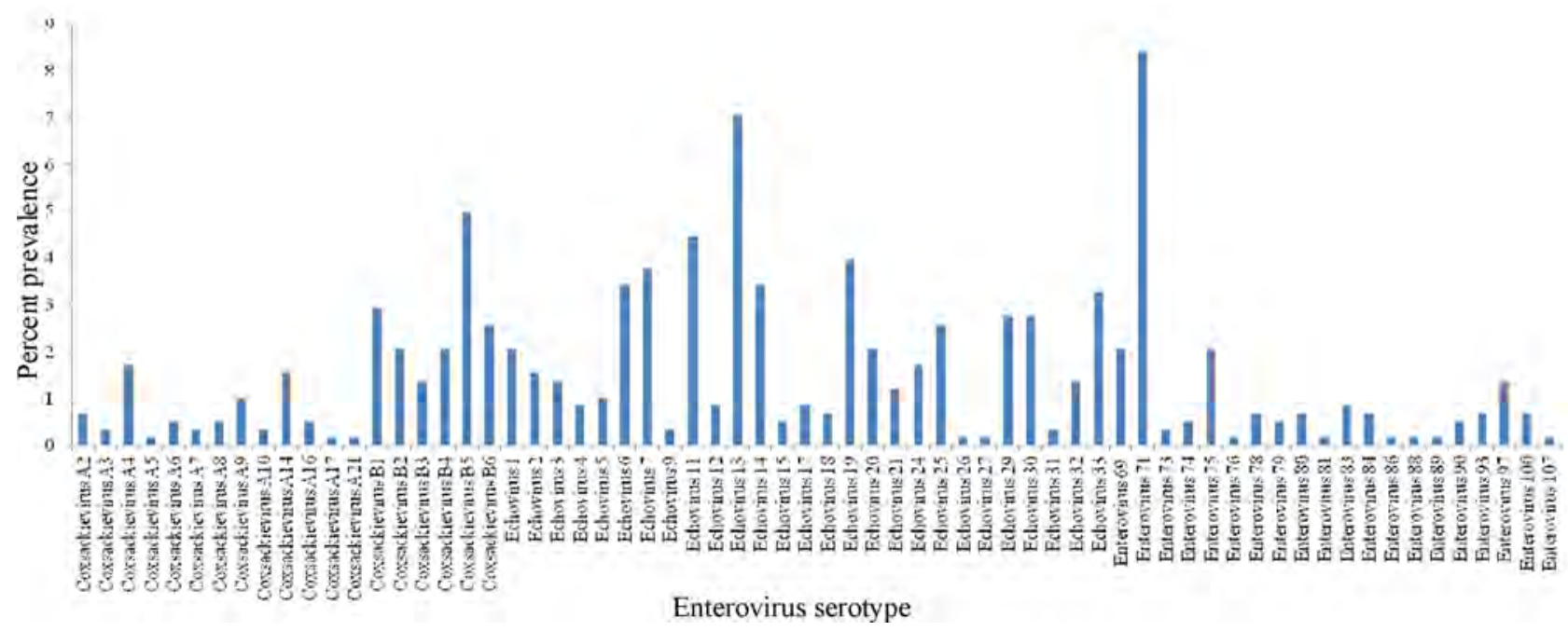

Fig. 3. Bar diagram representing the number and percentage of strains belonging to each serotype detected in AFP children

Among the NP-AFP patients, mixed infections involving more than one serotype were observed in 41 cases, of which; CVB4, CVB5, E6, EV69 and EV71 accounted for $12.2 \%, 12.2 \%$. 14.6\%, $17.1 \%$ and $31.7 \%$, respectively (Rao et al., 2012).

The most significant observation was that, EV71 was the single most prevalent serotype detected among NP-AFP patients, accounting for about $8.5 \%$ of the characterized isolates. Interestingly, EV71 appears to have spread from Kerala to Karnataka during 2008 and 2009, prior to which it was detected only in Kerala. Of note, about $26.5 \%$ of EV71 detections involved mixed infections (Rao et al., 2012). This observation is of great significance since EV71 is considered to be the most pathogenic enterovirus next to poliovirus, and is associated with severe poliomyelitis-like syndrome, brainstem disease, and HFMD (De et al., 2011; Ooi et al., 2010; Wang et al., 2004; Wu et al., 2010).

\section{Non-Polio Enteroviruses in Acute Diarrhoea}

Diarrhoeal diseases are still a major cause of morbidity and mortality in infants, young children and the elderly, and represent the third most frequent cause of death in children $<5$ years of age, primarily in developing countries, accounting for about 1.52.5 million deaths annually worldwide (Parashar et al.,2003a; World Health Report 2004; O’Ryan et al.,
2005). Every child suffers at least one episode of diarrhoea during the first few years of life. Although several infectious agents, viral, bacterial, protozoan, and non-infectious agents are associated with diarrhoea, about $40 \%$ of diarrhoeal cases are considered to be of unknown etiology (Denno et al., 2007; Greniger et al., 2009; Holtz et al., 2008; Holtz et al., 2009).

Among viral agents, rotavirus, astrovirus, calicivirus and adenovirus are associated with significant burden of the disease (Clark and McKendrick, 2004; Dennehy, 2005; Parashar et al., 2003b; Aijaz et al., 1996), rotavirus (RV) accounting for about $20-50 \%$ of the diarrheal cases in winter months and >450,000 deaths annually (Parashar et al., 2003b). In a few diarrheal patients, bocavirus, torovirus and picobirnavirus have been reported (Jamieson et al., 1998; Jin et al., 2011; Gallimore et al., 1995). A few picornaviruses including enteroviruses have been reported from a small number of sporadic diarrhoeal cases and as part of a few small-scale epidemiological studies (Harada et al., 2009; Harvala and Simmonds, 2009; Holtz et al., 2008, 2009; Nyangao et al., 2006; Kapoor et al., 2008; Patel et al., 1985; Phan et al., 2005; Patil et al., 2009; Yamashita et al., 1993; Rai et al., 2007; Scarcella et al., 2009, Silva et al., 2008), but their association with diarrhoea has not been seriously considered due 
to lack of detailed investigations. Further, a great majority of epidemiological studies failed to include enterovirus in the investigations. In order to conclusively demonstrate the association of enteroviruses with acute diarrhoea, we have conducted a 5-year long-term comparative molecular epidemiological investigation on rotavirus and enterovirus infections in diarrhoeic children, aged between zero and 9 years, reporting to paediatricians in Bangalore.

Surveillance of NPEV infections in India are extremely challenging, since every child undergoes polio vaccination 6-8 times during the first two years of life, resulting in many children often excreting the poliovirus vaccine strains. Several children receiving oral polio vaccine also develop diarrhoea. RT-PCR and sequence analysis of the VP1 gene was employed to distinguish poliovirus vaccine-associated diarrhoeal cases from NPEV-associated cases, and the polio vaccine-associated diarrhoeal cases were excluded from NPEV-associated diarrhoeal cases.

Comparative analysis of enterovirus and rotavirus infections from 2008 for five years revealed several surprising results. Of 2330 diarrheic samples analyzed during the five-year period from 2008-2012, the percent positivity for enterovirus ranged between $9.45 \%$ and $19.47 \%$ and that of rotavirus was between $8.1 \%$ and $21.06 \%$ (Fig. 4). While $16.31 \%$ of total diarrheal samples were NPEV-positive in RD cells, additional $2.7 \%$ of the RD-negative samples became positive by RT-PCR, which were mostly CVAs. Thus on the average, while about $19 \%$ of acute diarrhoea

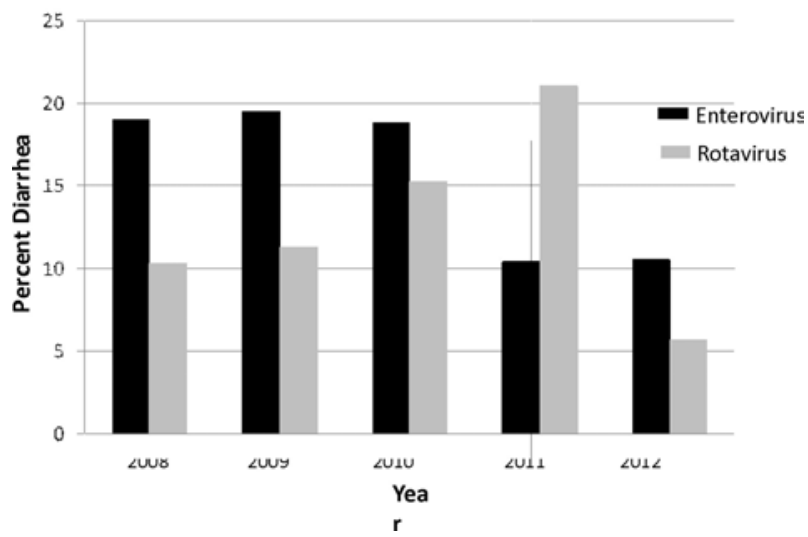

Fig. 4: Prevalence of rotavirus and enterovirus-associated diarrhoea in children from 2008 to 2012 samples (including $2.7 \%$ cell culture-negative but CVA-positive samples) were positive for NPEVs, $13.8 \%$ were positive for RV. About $1.8 \%$ of diarrhoeal children were positive for Oral Polio Vaccine (OPV) strains. Further, approximately, 6\% of 1700 specimens from a healthy follow-up cohort of children aged 0-9 years were also positive for NPEVs. Co-infection with EV and RV was observed in $0.64 \%$ of the diarrhoea samples. Examination of 300 samples each from diarrhoearic and healthy children revealed that $21 \%$ and $9 \%$ of the NPEV-negative samples, respectively, were positive for diarrhoeagenic E. coli. However, only $4 \%$ of NPEV-positive diarrhoea samples were positive for diarrhoeagenic $E$. coli (Rao et al., 2013).

Among children aged below three years, the average incidence of NPEV-associated diarrhoea ranged between $14 \%$ and $16 \%$ and that in children between three and nine years was between 21 and $27 \%$ during the five year period (Fig. 5). Although the number of children above three years having diarrhoea is significantly less than those below three years, the likelihood of NPEV infections resulting in diarrhoea appears to increase by 35\%-70\% in older children between three and nine years (Rao et al., 2013).

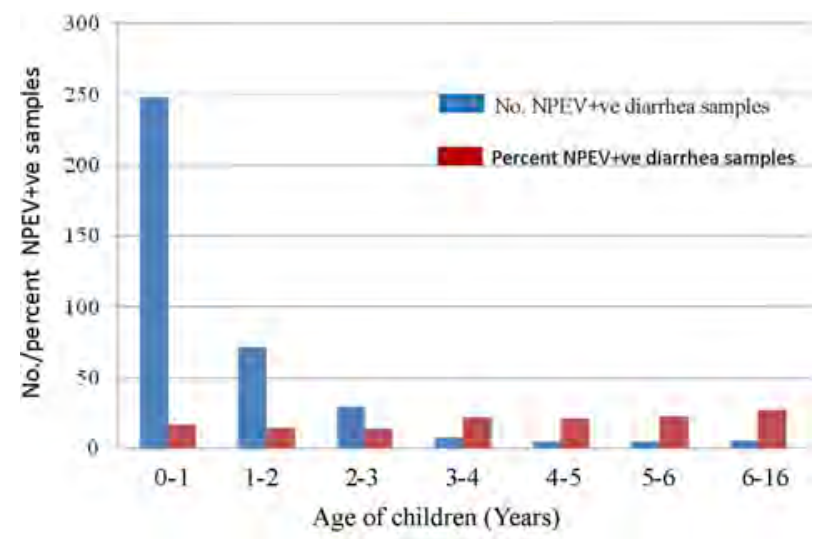

Fig. 5: Age-dependent prevalence of enterovirus diarrhoea in children aged $0-9$ years

\section{Contrasting Seasonal Predominance of EV And RV Diarrheal Infections}

A surprising finding of great clinical significance emerging from the long-term study on comparative 
acute diarrheal infections associated with EV and RV is the contrasting seasonal prevalence of the disease associated with the two agents. Month-wise analysis of the number of EV- and RV-associated diarrhoeal cases showed that, while RV-associated diarrhoea predominantly occurred in winter months (November to March), EV-associated diarrhoea was prevalent during other seasons spanning April to October (Fig. 6). While the frequency of RV diarrhoeal cases during winter months ranged between $8.0 \%$ and $57 \%$ (average 29\%), NPEV infections ranged between $0 \%$ and $10 \%$. By contrast, NPEV-associated acute diarrhoeal cases during April to October accounted for $14 \%$ to $50 \%$ (average $24 \%$ ) of the diarrhoeal cases and that due to RV ranged between $0 \%$ and $9 \%$. Seasonal prevalence of NPEV infections was also observed in healthy children, being $0 \%$ to $3 \%$ during winter months and $1 \%$ to $9 \%$ in other months (Rao et $a l ., 2013)$. Of note, majority of NPEV infections $(\sim 60 \%)$ occurred in children $<1$ year of age (Table $1)$, similar to that observed for rotavirus infections $(\sim 65 \%)$.

\section{EV Serotypes in Acute Diarrhoea}

Sequence analysis of NPEVs associated with acute diarrhoea revealed 37 serotypes among 242 sequenced RD-positive isolates. Echoviruses were predominantly associated with acute diarrhoea, rather than coxsackieviruses and newer enteroviruses combined together. Seven serotypes were more prevalent with the order of occurrence being
Table 1: Age dependent frequency of NPEV detection in children with acute diarrhoea

\begin{tabular}{lccc}
\hline Age & $\begin{array}{c}\text { No. } \\
\text { diarrhoeal specimens }\end{array}$ & $\begin{array}{c}\text { No. EV } \\
\text { positive }\end{array}$ & $\begin{array}{c}\% \\
\text { EV+ve }\end{array}$ \\
\hline $0-1 \mathrm{y}$ & 1496 & 246 & 16.37 \\
$1-2 \mathrm{y}$ & 493 & 72 & 14.60 \\
$2-3 \mathrm{y}$ & 224 & 33 & 14.73 \\
$3-4 \mathrm{y}$ & 41 & 9 & 21.95 \\
$4-5 \mathrm{y}$ & 28 & 7 & 25.00 \\
$5-6 \mathrm{y}$ & 26 & 7 & 26.92 \\
$6-9 \mathrm{y}$ & 22 & 6 & 27.27 \\
\hline
\end{tabular}

E11 $>$ E30 $>$ E7>E13>E33>E1>E14. Coxsackie B viruses represented $13 \%$ of the sequenced isolates. CVAs were not frequently detected in diarrhoeal children (Fig. 7) (Rao et al., 2013). The rate of detection of different serotypes differed each year and appeared to be associated with epidemics-like outbreaks due to specific serotypes.

\section{Genetic Diversity of Indian Enteroviruses Associated with NP-AFP and Acute Diarrhea}

Indian enteroviruses associated with NP-AFP (Fig. 8) and acute diarrhoea (Fig. 9) exhibited significant genetic diversity from those isolated in other countries (Rao et al., 2012; Rao et al., 2013). Phylogenetic analysis (Tamura et al., 2011) of VP1 sequences

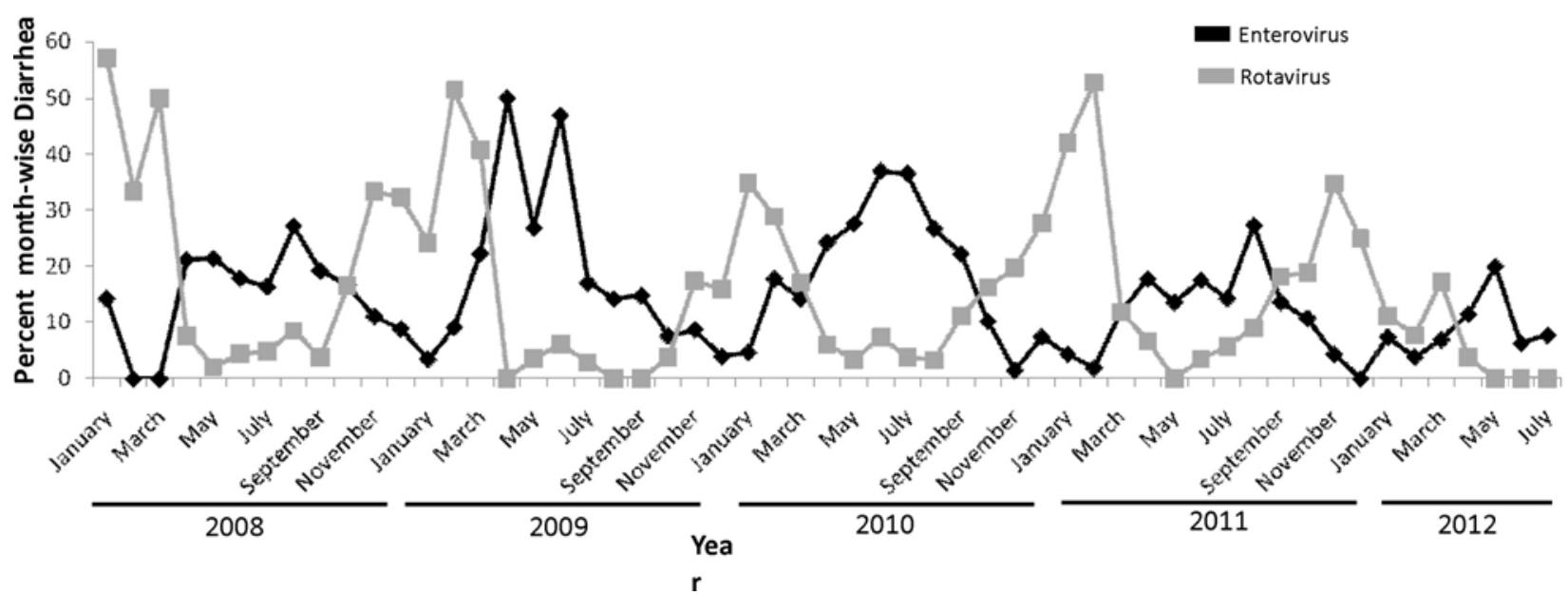

Fig. 6: Long-term analysis of the contrasting seasonal predominance of enterovirus and rotavirus diarrhoea 


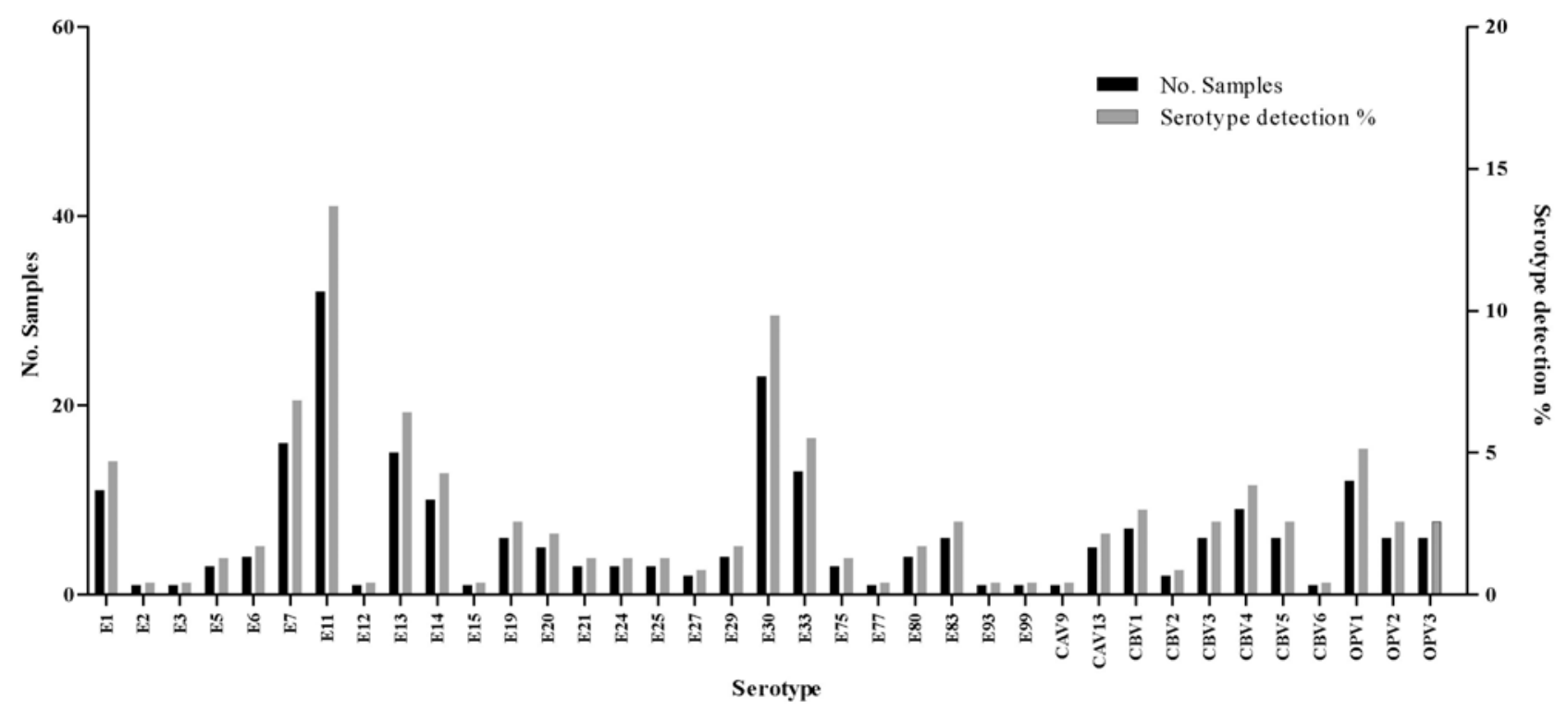

Fig. 7: Prevalence of Enterovirus serotypes associated with acute diarrhoea. Of the $380 \mathrm{EV}$ isolates, the VP1 gene from 294 could be amplified in RT-PCR. Serotypes were assigned for 242 isolates by VP1 sequence analysis and 52 isolates were not sequenced. Note that 86 (24\%) RD-positive isolates were negative for VP1 RT-PCR and hence are non-typeable

revealed that, Indian strains formed either new genogroups, and/or sub-genogroups within known genogroups. It should be noted that due to lack of sequence data on Indian enteroviruses, the primers were designed based on sequences of prototype and other strains isolated in other countries. The fact that we could not amplify the VP1 region from 15\%-30\% of isolates suggests possible failure of primers due to sequence diversity in Indian strains. The genetic diversity of E13 strains in India has been further corroborated recently (Maan et al., 2013).

\section{Emerging Eneterovirus Infections, and the Need for Active Research on Enteroviruses in India}

Considering the wide range of crippling and deadly diseases associated with enterovirus infections, the lack of active research on these viruses in India is of great concern. In recent years, small outbreaks of HFMD have been reported in India (Gopalakrishna et al., 2012; Kar et al., 2013; Sarma et al., 2009; Vijayaraghavan et al., 2012). A major outbreak of HFMD occurred in Bangalore in 2013, which affected not only several thousand children but also adults in the household (Times of India, 2013). Though EV71, CVA16 and CVA10 have been associated with HFMD in South East Asian countries, causing long-term crippling and neurological disorders, and significant number of deaths among children (Chen and Shih, 2011; Lee et al., 2009; Li et al., 2013; Lin et al., 2003; Ooi et al., 2010; Ortner et al., 2009), there is a dearth of knowledge in India on the nature or genetic diversity of the viruses associated with the disease. For the last few years, encephalitis in UP has claimed several lives of children. Though these cases were originally presumed to be due to Japanese encephalitis virus, they turned out to be negative for JEV. A few investigations revealed enterovirus association with these encephalitis cases (Joshi et al., 2012; Joshi et al., 2013; Sapkal et al., 2009; Kumar et al., 2011; Kumar et al., 2012; Lewthwaite et al., 2010), but there is no consensus on the serotype/s associated with the disease. Similarly, a few epidemiological studies on aseptic meningitis and acute hemorrhagic conjunctivitis cases from different regions of the country have been reported (Gopalakrishna 2007; Kumar et al., 2013; Madhavan et al., 2000; Maitreyi et al., 1999; Satpathy et al., 1996; Shukla et al., 2010), but a detailed analysis needs to be carried out. There is an urgent need to focus our research on enteroviruses and include these neglected ubiquitous viruses in future epidemiological studies on various diseases for which definitive causes have not been established. 


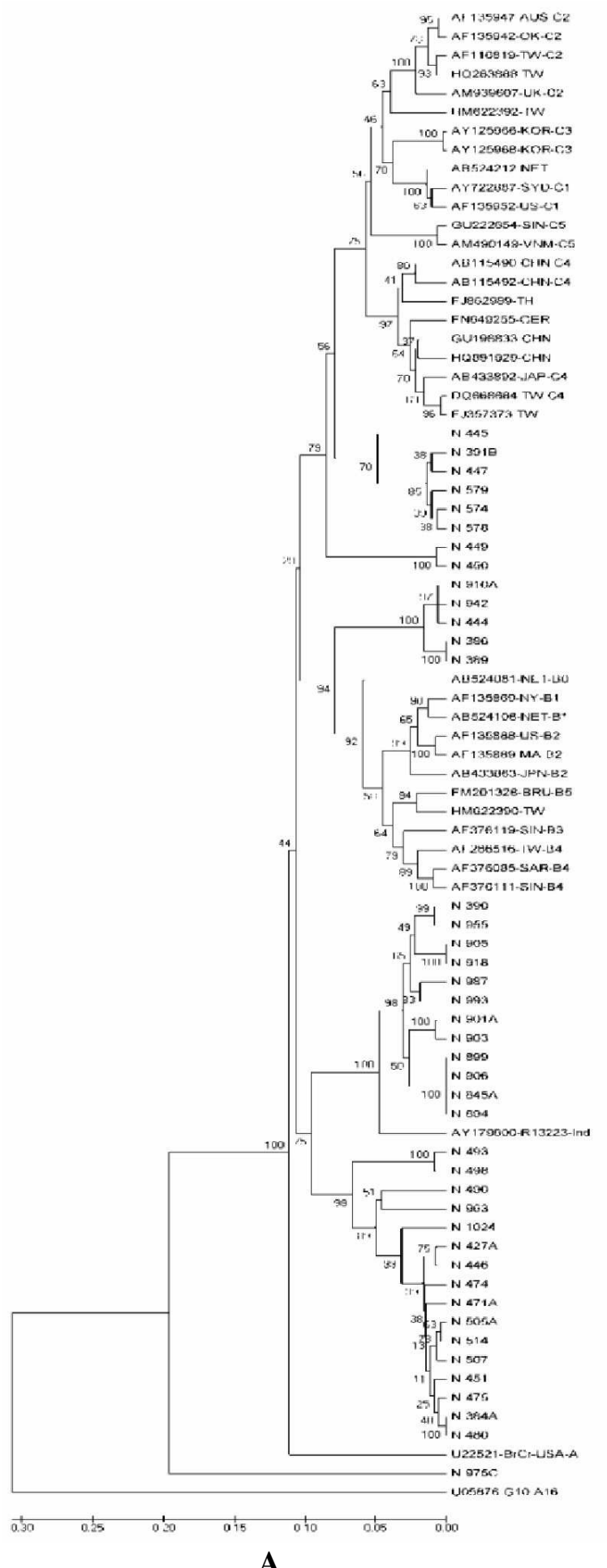

A

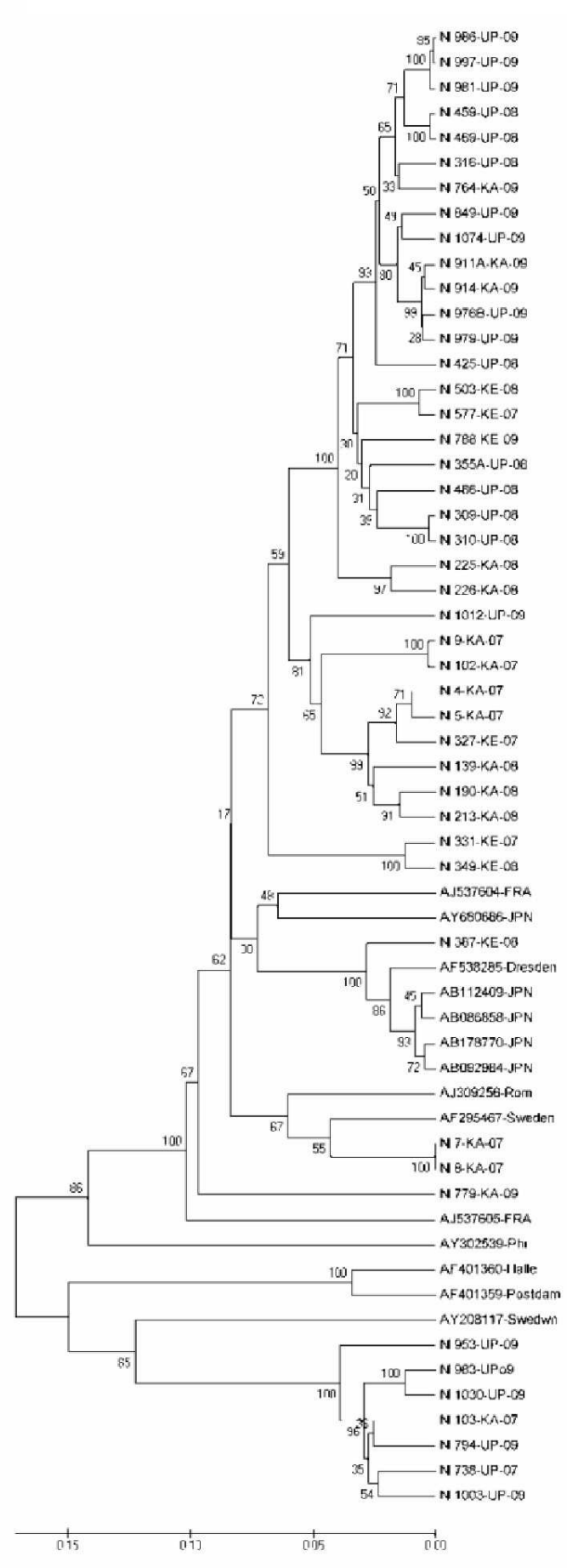

B

Fig. 8: Phylogenetic analyses of VP1 sequences of Indian EV71 and E13 strains with those of reference strains belonging to different genogroups and subgenogroups within a serotype. Multiple sequence alignments were performed using ClustalW program and phylogenetic analysis by MEGA 5 program employing pairwise comparison and maximum composite likelihood nucleotide substitution model (Tamura et al., 2011). Phylogenetic trees were constructed by UPGMA method with statistical significance of the phylogenetic analyses estimated by bootstrap analysis with 1000 pseudo-replicate data sets. A and B represent phylogenetic trees of VP1 sequences of EV71 and E13 isolates, respectively. The serotype, state and year of isolation of each strain and accession numbers of reference strains used are indicated. 1000B is an echovirus 1 strain. The VP1 gene accession numbers of 618 Indian NP-AFP isolates are HQ454497 to 454499 and JN203499 to JN204113 

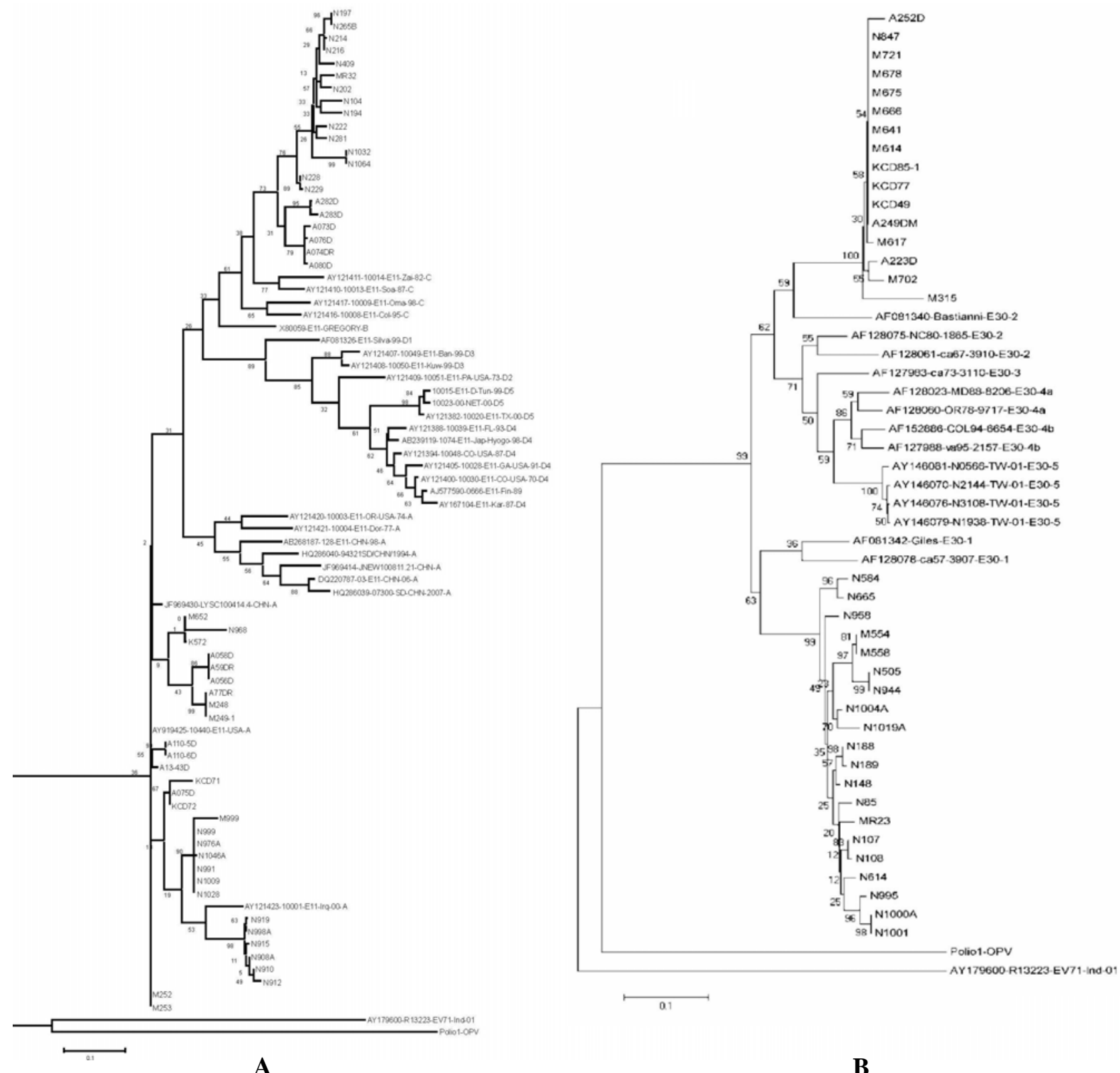

Fig. 9: Phylogenetic analysis of VP1 gene sequences of NPEV strains representing the prevalent serotypes E11 and E30 associated with acute diarrhoea. Details of phylogenetic analysis are described in the legend to Fig. 7. The tree inference was by Nearest-Neighbor-Interchange Heuristic Method. Multiple sequence alignments were performed by using ClustalW program and phylogenetic analysis by MEGA5.5 program (Tamura et al., 2011) with Kimura-2-parameter substitution model. Note distinct sub-genogroups formed by Indian diarrhoeal isolates and NP-AFP strains (numbers preceded by letter N). The GenBank accession numbers of VP1 sequences from 166 diarrhoeal isolates are from JX513427-JX513605. Sequences of 76 isolates are not submitted as they are either identical to some of the submitted sequences or represent OPV strains. Strain numbers preceded by letter ' $N$ ' refer to NPEVs recently reported by us from AFP patients from India (Rao et al., 2012). E11 and E30 reference strains belonging to different genogroups used in phylogenetic analysis are indicated by their GenBank accession numbers followed by strain names. (A) Phylogenetic tree for VP1 gene sequences of representative E11 strains, and (B) that of E30 strains

\section{Conclusions}

Although enteroviruses are common and associated with a wide range of diseases in humans, especially in children, they have been neglected to be investigated in gastrointestinal diseases. In fact, very few studies on acute diarrhoea have examined enteroviruses. Due to lack of detailed studies on enterovirus association with acute diarrhoea, they 
have not been recognized as a significant cause of gastrointestinal disease. A great majority of epidemiological studies have been focussed on rotavirus, as it is considered to be the major causative agent of acute diarrhoea in infants and young children. However, all the rotavirus-centric studies are primarily focussed during winter months as rotavirus infections predominantly occur in the winter season. As enterovirus was not examined in majority of the epidemiological studies on diarrhoea, and EVs were not detected in significant numbers in winter months in comparison to rotavirus, it appears to have been presumed that EVs are not a significant cause of diarrhoea, and hence, have been neglected and not included in most epidemiological studies. Our longterm studies clearly demonstrated that EV-associated diarrhoea predominantly occurs during springsummer-fall seasons, in contrast to rotavirus diarrhoea, which occurs primarily in winter months. Further, these studies revealed for the first time that EV-associated diarrhoea is as significant, or more significant, as rotavirus diarrhoea. Based on severe diseases such as poliomyelitis, aseptic meningitis, etc., it was considered that less than $1.0 \%$ of enterovirus infections are associated with disease in humans. Our results on the role of NPEVs in acute diarrhoea alone reveal that enteroviruses are associated with approximately $20 \%$ of the disease. Our studies, for the first time, identified NPEVs as a major cause of acute diarrhoea in children and suggested that, echoviruses, representing a major proportion of EVs associated with diarrhoea, as well as NP-AFP, should no longer be considered as orphan viruses.

Epidemiological survey of NPEV infections in children (in USA) from 1970-2005 revealed that about $44 \%$ of infections occurred in children $<1$ year of age and summer-fall seasonality of enterovirus infections (Khetsuriani et al., 2006a, 2006b). Though our results are in concurrence with the reported observations, NPEV infections in diarrhoeric children below one year of age are significantly higher in India amounting to $60 \%$ of NPEV infections, among children aged 0-9 years (Rao et al., 2013). While, $80 \%$ of EV-associated diarrhoeal infections occurred in children $<2$ years of age, the number of EV- associated diarrhoeal cases as well as total number of diarrheal cases steeply decreased with age (Fig. 5 and Table 1). About $65 \%$ of rotaviral infections also occurred in children aged $<1$ year. Our studies further revealed that while majority of EV infections during the first year are apparently asymptomatic, the likelihood of, or percent of children becoming positive for NPEV increased by about 2-fold among older children suffering from acute diarrhoea (Rao et al., 2013). Though the summer-fall seasonality of $\mathrm{EV}$ infections is known, our novel observation is the contrasting seasonality between rotavirus diarrhoea and enterovirus diarrhoea, which has never been described prior to our studies. The serotypes identified in Indian children are similar to those reported in other studies, but our studies could identify more number of serotypes. It is yet to be understood how the serotype prevalence could differ with time and season.

As with rotavirus-associated infections, no mortality in children with EV infections during our study was observed since the subjects are from urban area, and have access to healthcare facilities. Majority of the infantile diarrhoeal deaths occur in rural and tribal areas due to limited access to healthcare facilities in contrast to urban settings. We have not examined CSF samples in any of the subjects, because such procedures are required only for infections of brain and central nervous system causing aseptic meningitis (Shukla et al., 2013), acute encephalitis (Kumar et al., 2011; Kumar et al., 2012), brainstem disease (Xing et al., 2014) etc. No serious neurological complications or HFMD have been observed in the diarrhoeal children, but about $20 \%$ of the subjects had either common cold, non-febrile illness or respiratory illness, suggesting that, EV infections are also associated with other symptoms along with diarrhoea. The symptoms of enterovirus infections range from asymptomatic to mild symptoms to serious complications and death. EVs are also known to cause persistent infections in humans, lasting for several months (Martin 2004; Martin 2006; Li et al., 2013). This wide variation in the degree of disease symptoms likely reflects the significant genetic variation not only among different enterovius serotypes, but within strains belonging to 
the same serotype (Borzakian et al., 1993; Duncan et al., 1998; Ramsingh and Collins 1995; Coleman et al., 2008; Yetterberg et al., 1987; Song et al., 2012; Rao et al., 2012; Rao et al., 2013; Rao et al., 2014).

It has been estimated that about 15 million cases of EV infections occur in children in USA alone and about one billion infections worldwide each year (Lukashev et al., 2010; Pallansch and Roos 2007). Our recent two-year follow-up study revealed that every child had more than one infection during the first two years of life, with majority of the infections lasting less than a week and about $6 \%$ becoming persistent, some of them prolonging for more than three months (Rao et al., 2014). Since systematic epidemiological studies on incidence of enterovirus infections in infants and young children, ranging from birth to two years of age are lacking in both developed and developing countries, especially their role in acute and persistent diarrhoea, it is difficult to assess the total burden of enterovirus infections in the world. Further, as enteroviruses are associated with a wide range of diseases not only in children but also in adults, an integrated approach for assessment of the burden of EV infections, the diseases and the economic cost is urgently required to appreciate the total burden, and development of strategies for an effective management of child healthcare system.

In recent years, outbreaks of acute encephalitis syndrome have been frequently reported in northern India and other countries. A major proportion of these cases appear to be of non-Japanese Encephalitis Virus etiology, and enteroviruses have been implicated (Kakkar et al., 2013; Kumar et al., 2011; Kumar et al., 2012; Fowlkes et al., 2008; Sapkal et al., 2009; Joshi et al., 2012; Joshi et al., 2013; Reingold et al., 2013) and there is a need for systematic detailed study of the disease (Kakkar et al., 2013). Though epidemics of hemorrhagic conjunctivitis and handfoot-and mouth disease associated with enterovirus infections are being reported in the news (Times of India 2013) frequently from different parts of the country, very few have been investigated (Deshpande et al., 2003; Gopalakrishna et al., 2007; Gopalakrishna et al., 2012; Maitreyi et al., 1999; Madhavan et al., 2000). HFMD has become endemic and emerged as a major child health threat/hazard in
Southeast Asian countries including China, Taiwan, Thailand, Singapore, Malaysia, Cambodia and Vietnam (Christian et al., 2013; Chua et al., 2011; Lee et al., 2012; WPRO-WHO 2013; Wu et al., 2010). The close economic cooperation between India and Southeast Asian countries and the high volume of travel between the regions appear to have resulted in the establishment and spread of HFMD in India during the last 5-7 years (Rao et al., 2012). Recent emergence of EV68 as a significant cause of severe respiratory infections and polio-like illness in USA and other countries is of great concern (Centers for Disease Control and Prevention 2011, 2014; Lu et al., 2014). With the advent of HFMD in India in epidemic form in recent years, and implication of enterovirus in encephalitis in Uttar Pradesh, time has arrived that these so far neglected and unrecognized viruses are considered as the emerging threats to child health management in the country, and due importance is given for clinical, basic and translational research on these viruses to meet unforeseen challenges that might emerge in future.

A wide spectrum of acute and chronic diseases caused by EVs are a significant cause of social and economic loss. Influenza-like illness and mild forms of enterovirus infection (herpangina, exanthema) are widespread, necessitating frequent visits to clinics. Though the economic cost of mild form of enterovirus infection is not high, the sheer number of infections (10-15 million cases yearly in USA alone and $>1$ billion worldwide) signifies the economic burden. Outbreaks of enterovirus aseptic meningitis, nonpolio AFP and encephalitis cause significant economic burden due to hospitalization costs. EVs are also associated with $30 \%$ of sepsis-like disease in newborns, resulting in significant infant morbidity and mortality (Lukashev et al., 2010). The $20^{\text {th }}$ century has witnessed enteroviruses as a major cause of pandemics of paralytic poliomyelitis, hemorrhagic conjunctivitis, and HFMD, causing severe social and economic loss. With the eradication of wild poliovirus transmission in the country, NPEVs are likely to occupy the centre stage in the category of major human pathogens associated with emerging and yet to be recognized human and animal diseases in the 21 st century. 


\section{References}

Aijaz S, Gowda K, Jagannath HV, Reddy RR, Maiya PP, Ward RL, Greenberg HB and Rao CD (1996) Epidemiology of symptomatic human rotaviruses in Bangalore and Mysore, India, from 1988 to 1994 as determined by electropherotype, subgroup and serotype analysis Arch Virol 141 715-726

Avellon A, Casas I, Trallero G, Perez C, Tenerio A and Palacios G (2003) Molecular analysis of echovirus 13 isolates and aseptic meningitis, Spain Emerg Infect Dis 8 934-941

Bingjun T, Yoshida H, Yan W, Lin L, Tsuji T, Shimizu H and Miyamura T (2008) Molecular typing and epidemiology of non-polio enteroviruses isolated from Yunnan province, the People's Republic of China J Med Virol 80 670-679

Borzakian S, Pelletier I, Calvez V and Colbere-Garapin F (1993) Precise missense and silent point mutations are fixed in the genomes of poliovirus mutants from persistently infected cells J Virol 67 2914-2917

Centers for Disease Control and Prevention (2014) Severe respiratory illness associated with enterovirus D68Missouri and Illinois Morb Mortal Wkly Rep 63 1-2

Centers for Disease Control and Prevention (2011) Clusters of acute respiratory illness associated with human enterovirus 68-Asia, Europe, and United States, 2008-2010 Morb Mortal Wkly Rep 60 1301-1304

Centers for Disease Control and prevention (CDC) (2010) Progress toward poliomyelitis eradication-India, January 2009-October 2010 Morb Mortal Wkly Rep 59 1581-1585

Centers for Disease Control and Prevention (2003) Outbreaks of aseptic meningitis associated with echoviruses 9 and 30 and preliminary surveillance reports on enterovirus activity-United States, 2003. Morb Mortal Wkly Rep 52 761-764

Chen T-C and Shih S-R (2011) Drug discovery in enteroviral infections Infect Disord Drug Targets 11 337-345

Christian KA, Ijaz K, Dowell SF, Chow CC, Chitale RA, Bresee JS, Mintz E, Pallansch MA, Wassilak S, McCray E and Arthur RR (2013) What we are watching-five top global infectious disease threats, 2012: a perspective from CDC's global disease detection operations center Emerg Health Threats J 620632

Chua KB, and Kasri AR (2011) Hand foot and mouth disease due to enterovirus 71 in Malaysia Virol Sin 26 221-228

Clark B and McKendrick M (2004) A review of viral gastroenteritis Curr Opin Infect Dis 17 461-469

Coleman JR, Papamichail D, Skiena S, Futcher B, Wimmer E and Mueller S (2008) Virus attenuation by genome-scale changes in codon pair bias Science 320 1784-1787
De W, Changwen K, Wei L, Monaqin C, Jin Y, Cong M, Hanri Z and Jun S (2011) A large outbreak of hand, foot, and mouth disease caused by EV71 and CAV16 in Guangdong, China, 2009 Arch Virol 156 945-953

Dennehy P H (2005) Acute diarrheal disease in children: epidemiology, prevention, and Treatment Infect Dis Clin North Am 19 585-602

Denno DM, Klein EJ, Young VB, Fox JG, Wang D and Tarr PI (2007) Explaining unexplained diarrhea and associating risks and infections Anim Health Res Rev 8 69-80

Deshpande JM, Nadkarni SS and Francis PP (2003) Enterovirus 71 isolated from a case of acute flaccid paralysis in India represents a new genotype Current Science 84 1350-1353

Dhole TN, Ayyagari A, Chowdhary R, Shakya A K, Shrivastav N, Datta T and Prakash (2009) Non-polio enteroviruses in acute flaccid paralysis children of India: vital assessment before polio eradication J Paediatr Child Health 45 409413

Duncan G, Pelletier I and Colbere-Garapin F (1998) Two amino acid substitutions in the type 3 poliovirus capsid contribute to the establishment of persistent infection in Hep-2c cells by modifying virus-receptor interactions Virology 241 1429

el-Sageyer MM, Szendroi A, Hutter E, Uj M, Szucs G, Mezey I, Toth I, Katai A, Kapiller Z, Pall G, Petras G, Szalay E, Mihaly I, Gourova S and Berencsi G (1998) Characterization of an echovirus type 11' (prime) epidemic strain causing haemorrhagic syndrome in newborn babies in Hungary Acta Virol 42 157-166

Field Guide: Surveillance of acute flaccid paralysis. Third Edition. Child health Division, Department of Family Welfare, Ministry of Health \& Family Welfare, New Delhi, September 2005

Fowlkes AL, Honarmand S, Glaser C, Yagi S, Schnurr D, Oberste MS, Anderson L, Pallansch MA and Khetsuriani N (2008) Enterovirus-associated encephalitis in the California encephalitis project, 1998-2005 J Infect Dis 198 16851691

Gallimore CI, Appleton H, Lewis D, Green J and Brown DW (1995) Detection and characterization of bisegmmented double-stranded RNA viruses (picobirnaviruses) in human fecal specimens J Med Virol 45 135-140

Global Polio Eradication Initiative (2011) (Accessed April 21, 2014 at http://www. polioeradication.org/)

Gopalkrishna V, Patil PR, Patil GP and Chitambar SD (2012) Circulation of multiple enterovirus serotypes causing hand, foot and mouth disease in India J Med Microbiol 61 420425 
Gopalkrishna V, Patil PR, Kolhapure RM, Bilaiya H, Fulmali PV and Deolankar RP (2007) Outbreak of acute hemorrhagic conjunctivitis in Maharashtra and Gujarat states of India, caused by Coxsackie virus A-24 variant $J$ Med Virol 79 748-753

Greniger AL, Runckel C, Chiu CY, Haggerty T, Parsonnet J, Ganem D and DeRisi JL (2009) The complete genome of klassevirus-a novel picornavirus in pediatric stool Virol $J$ 682

Harada S, Okada M, Yahiro S, Nishimura K, Matsuo S, Miyasaka J, Nakashima R, Shimada Y, Ueno T, Ikezawa S, Shinozaki K, Katayama K, Wakita T, Takeda N and Oka T (2009) Surveillance of pathogens in outpatients with gastroenteritis and characterization of sapovirus strains between 2002 and 2007 in Kumamoto Prefecture, Japan J Med Virol 81 1117-1127

Harvala H and Simmonds P (2009) Human parechoviruses: Biology, epidemiology and clinical significance. J Clin Virol 45 1-9

Hinkkanen AE (2003) Molecular epidemiology of enteroviruses causing eveitis and multisystem hemorrhagic disease of infants Virology 307 45-53

Holtz LR, Finkbeiner SR, Kirkwood CD and Wang D (2008) Identification of a novel picornavirus related to cosaviruses in a child with acute diarrhea Virol J 5159

Holtz LR, Finkbeiner SR, Zhao G, Kirkwood CD, Girones R, Pipas JM and Wang D (2009) Klassevirus I, a previously undescribed member of the family picornaviridae, is globally widespread Virology J 686

Jamieson FB, Wang EE, Bain C, Good J, Duckmanton L and Petric M (1998) Human torovirus: a new nosocomial gastrointestinal pathogen J Infect Dis 178 1263-1269

Jin Y, Cheng WX, Xu ZQ, Liu N, Yu JM, Li HY, Jin M, Li DD, Zhang Q and Duan ZJ (2011) Highprevalence of human bocavirus 2 and its role in childhood acute gastroenteritis in China J Clin Virol 52 251-253

Joshi R, Kalantri SP, Reingold A and Colford JM Jr (2012) Changing landscape of acute encephalitis syndrome in India: a systematic review Natl Med J India 25 212-220

Joshi R, Mishra PK, Joshi D, Santhosh SR, Parida MM, Desikan P, Gangane N, Kalantri SP, Reingold A and Colford JM Jr (2013) Clinical presentation, etiology, and survival in adult acute encephalitis syndrome in rural Central India Clin Neurol Neurosurg 115 1753-1761

Kakkar M, Rogawski ET, Abbas SS, Chaturvedi S, Dhole TN, Hossain SS and Krishnan SK (2013) Acute encephalitis syndrome surveillance, Kushinagar district, Uttar Pradesh, India, 2011-2012 Emerg Infect Dis 19 1361-1367
Kapoor A, Victoria J, Simmonds P, Slikas E, Chieochansin T, Naeem A, Shaukat S, Sharif S, Alam MM, Angez M, Wang C, Shafer RW, Zaidi S and Delwart E (2008) A highly prevalent and genetically diversified picornaviridae genus in South Asian children Proc Natl Acad SciUSA 105 20482-20487

Kar BR, Dwibedi B and Kar SK (2013) An outbreak of hand, foot and mouth disease in Bhubaneswar, Odisha. Indian Pediatr 50 139-142

Khetsuriani N, Lamonte-Fowlkes A, Oberst S and Pallansch MA (2006a) Centers for Disease Control and Prevention. Enterovirussurveillance-United States, 1970-2005 Morb Mortal Wkly Rep 55 1-20

Khetsuriani N, Lamonte A, Oberste MS and Pallansch M (2006b) Neonatal enterovirus infections reported to the national enterovirussurveillance system in the United States, 19832003 Pediatr Infect Dis J 25 889-93

Kumar A, Shukla D, Kumar R, Idris MZ, Misra UK and Dhole TN (2011) An epidemic of encephalitis associated with human enterovirus B in Uttar Pradesh, India J Clin Virol 51 142-145

Kumar A, Shukla D, Kumar R, Idris MZ, Misra UK and Dhole TN (2012) Molecular epidemiological study of enteroviruses associated with encephalitis in children from India J Clin Microbiol 50 3509-3512

Kumar A, Shukla D, Kumar R, Idris MZ, Jauhari P, Srivastava S and Dhole TN (2013) Molecular identification of enteroviruses associated with aseptic meningitis in children from India Arch Virol 158 211-215

Lashkevich VA, Koroleva GA, Lukashev AN, Denisova EV and Katargina LA (2004) Enterovirus uveitis Rev Med Virol 14 241-254

Laxmivandana R, Yergolkar P, Gopalkrishna V and Chitambar SD (2013) Characterization of the non-polio enterovirus infections associated with acute flaccid paralysis in SouthWestern India PLoS One 8 e61650 doi: 10.1371/ journal.pone.0061650

Lee TC, Guo HR, Su HJ, Yang YC, Chang HL and Chen KT (2009) Diseases causedbyenterovirus71 infection Pediatr Infect Dis J 28 904-910

Lewthwaite P, Perera D, Ooi MH, Last A, Kumar R, Desai A, Begum A, Ravi V, Shankar MV, Tio PH, Cardosa MJ and Solomon T (2010) Enterovirus 75 encephalitis in children, southern India Emerg Infect Dis 16 1780-1782

Li J, Lin C, Qu M, Li X, Gao Z, Zhang X, Liu Y, Huang Y, Wang X, Jia L, Li X, Liu G, Yan H, Chen L and Wang Q (2013) Excretion of enterovirus 71 in persons infected with hand, foot and mouth disease Virol J 1013 
Lin TY, Twu SJ, Ho MS, Chang LY and Lee CY (2003) Enterovirus 71 outbreaks, Taiwan: Occurrence and recognition Emerg Infect Dis 9 291-293

Lu QB, Wo Y, Wang HY, Wei MT, Zhang L, Yang H, Liu EM, Li TY, Zhao ZT, Liu W and Cao WC (2014) Detection of enterovirus 68 as one of the commonest types of enterovirus found in patients with acute respiratory tract infection in China J Med Microbiol 63 408-414

Lukashev AN, Lashkevich VA, Koroleva GA, IIonen, J, Karganova GG, Reznik VI and Hinkkanen AE (2003) Molecular epidemiology of enteroviruses causing uveitis and multisystem hemorrhagic disease of infants Virology $30745-53$

Madhavan HN, Malathy J and Priya K (2000) An outbreak of acute conjunctivitis caused by Coxsackie virus A 24 Indian J Ophthalmol 48159

Maitreyi RS, Dar L, Muthukumar A, Vajpayee M, Xess I, Vajpayee RB, Seth P and Broor S (1999) Acute hemorrhagic conjunctivitis due to enterovirus 70 in India Emerg Infect Dis 5 267-269

Maan HS, Chowdhary R, Shakya AK and Dhole TN (2013) Genetic variants of echovirus 13, northern India, 2010 Emerg Infect Dis 19 293-296

Martin J, Odoom K, Tuite G, Dunn G, Hopewell N, Cooper G, Fitzharris C, Butler K, Hall WW and Minor PD (2004) Long-term excretion of vaccine-derived poliovirus by a healthy child J Virol 78 13839-13847

Martin J (2006) Vaccine-derived poliovirus from long-term excretors and the end game of polio eradication Biologicals 34 117-122

Moldin JF (1986) Perinatal echovirus infection: insights from a literature review of 61 cases of serious infection and 16 outbreaks in nurseries Rev Infect Dis 8 918-926

Moldin JF (1980) Fatal echovirus disease in premature neonates Pediatrics 66 775-780

Mostoufizadeh M, Lack EE, Gang, DL, Perez-Atayde AR and Driscoll SG (1983) Postmortem manifestations of echovirus 11 sepsis in five newborn infants Hum Pathol 14 818-823

National polio surveillance Project A government of India-WHO collaboration (Accessed, April 24, 2014 at http:// www.npspindia.org/)

Nyangao JW, Kingori P and Okoth FA (2006) Detection and identification of echovirus 7 from a child with gastroenteritis East Afr Med J 83 666-669

Oberste MS, Maher K, Flemister MR, Marchetti G, Kilpatrick DR and Pallansch MA (2000) Comparison of classic and molecular approaches for the identification of untypeable enteroviruses J Clin Microbiol 38 1170-1174

Ooi MH, Wong SC, Lewthwaite P, Cardosa MJ and Solomon T (2010) Clinical features, diagnosis, and management of enterovirus 71 Lancet Neurol 9 1097-1105

Ortner B, Huang C-W, Schmid D, Mutz I, Wewalka G, Allerberger F, Yang JY and Huemer HP (2009) Epidemiology of enterovirus types causing neurological disease in Austria 1999-2007: detection of clusters of echovirus 30 and enterovirus 71 and analysis of prevalent genotypes $J$ Med Virol 81 317-324

O'Ryan M, Prado V and Pickering LK (2005) A millennium update on pediatric diarrheal illness in the developing world Semin Pediatr Infect Dis 16 125-136

Pallansch M and Roos R (2007) Enteroviruses: Polioviruses, Coxsackieviruses, echoviruses, and newer enterovirusesIn:Fields Virology(Knipe DM, Howley PM, Griffin D E, Martin M A, Lamb R A, Roizman B, Straus S E eds) pp 839-893, Wolters Kluver, Lippincott, Williams \& Wilkins

Parashar UD, Bresee JS and Glass RI (2003a) The global burden of diarrheal disease in children Bull World health Org $\mathbf{8 1}$ 236

Parashar UD, Hummelman EG, Bresee JS, Miller MA and Glass RI (2003b) Global illness and deaths caused by rotavirus disease in children Emerg Infect Dis 9 565-572

Patel JR, Daniel J and Mathan VI (1985) An epidemic of acute diarrhea in rural southern India associated with echovirus type 11 infection J Hyg (Lond) 95 483-492

Patil PR, Chitamber SD and Gopalakrishna V (2009) Molecular detection of enteroviruses among children hospitalized with acute gastroenteritis from Pune, Maharashtra Ind $J$ Virol 20 P12

Persu A, Baicus A, Stavri S and Combiescu M (2009) Non-polio enteroviruses associatedwith acute flaccid paralysis (AFP) and facial paralysis (FP) cases in Romania, 2001-2008. Roum Arch Microbiol Immunol 68 20-26

Phan TG, Nguyen TA, Shimizu H, Yagyu F, Okitsu S, Muller WE and Ushijima H (2005) Identification of enteroviral infection among Infants and children admitted to hospital with acute gastroenteritis in Ho Chi Minh City, Vietnam $J$ Med Virol 77 257-264

Picornavirus Home accessed April 20, 2014 at http:// www.picornaviridae.com.

Rai BS, Wan Mansor H, Vasantha T, Norizah I and Chua KB (2007) An outbreak of echovirus 11 amongst neonates in a confinement home in Panang, Malaysia Med J Malaysia 62 223-226 
Ramsingh AI and Collins DN (19950 A point mutation in the VP4 coding sequence of coxsackievirus B4 influences virulence $J$ Virol 69 7278-7281

Rao CD, Ananda Babu M, Raghavendra A, Dhananjaya D, Sudheendra K and Maiya PP (2013) Non-polio enteroviruses and their association with acute diarrhea in children in India Infect Genet Evol 17 153-161

Rao DC, Reddy H, Sudheendra K, Raghavendra A, Varadharaj V, Edula S, Goparaju R, Ratnakar B, Rao ASRS, Maiya PP and Babu MA (2014) Non-polio enterovirus association with persistent diarrhea in children as revealed by a followup study of an India cohort during the first two years of life J Clin Virol 61 125-131

Rao CD, Yergolkar P and Shankarappa KS (2012) Analysis of antigenic diversity of enteroviruses associated with nonpolio acute flaccid paralysis, India, 2007-2009 Emerg Infect Dis 18 1833-1840

Reyes MP, Ostrea EM Jr, Roskamp J and Lerner AM (1983) Disseminated neonatal echovirus disease following antenatal maternal infection with a virus-positive cervix and virus- negative gastrointestinal tract J Med Virol 12 155-159

Saeed M, Zaidi SZ, Naeem A, Masroor M, Sharif S, Shaukat S, Angez M and Khan A (2007) Epidemiology and clinical findings associated with enteroviral acute flaccid paralysis in Pakistan BMC Infect Dis 15 7-6

Sapkal GN, Bondre VP, Fulmali PV, Patil P, Gopalkrishna V, Dadhania V, Ayachit VM, Gangale D, Kushwaha KP, Rathi AK, Chitambar SD, Mishra AC and Gore MM (2009) Enteroviruses in patients with acute encephalitis, uttar pradesh, India Emerg Infect Dis 15 295-298

Sarma N, Sarkar A, Mukherjee A, Ghosh A, Dhar S and Malakar $R$ (2009) Epidemic of hand, foot and mouth disease in West Bengal, India in August, 2007: a multicentric study Indian J Dermatol 54 26-30

Satpathy G, Mohanty S and Nayak N (1996) An epidemic of viral acute haemorrhagic conjunctivitis in Delhi in 1994 Indian J Ophthalmol 44 19-21

Scarcella C, Carsi S, Cadoria F, Macchi L, Pavan A, Salamana M, Alborali GL, Losio MN, Boni P, Lavazza A and Seyler T (2009) An outbreak of viral gastroenteritis linked to municipal water supply, Lombardy, Italy, June 2009 Euro Surveill 14 Pii:19274

Shukla D, Kumar A, Srivastava S and Dhole TN (2013) Molecular identification and phylogenetic study of coxsackievirus A24 variant isolated from an outbreak of acute hemorrhagic conjunctivitis in India in 2010 Arch Virol 158 679-684

Silva PA, Stark K, Mockenhaupt FP, Reither K, Weitzel T, Ignatius
R, Saad E, Seidu-Korkor A, Bienzle U and Schreier E (2008) Molecular characterization of enteric viral agents from children in northern region of Ghana J Med Virol $\mathbf{8 0}$ 1790-1798

Solomon T and Willison H (2003) Infectious causes of acute flaccid paralysis Curr Opin Infect Dis 16 375-81

Song Y, Liu Y, Ward CB, Mueller S, Futcher B, Skiena S, Paul $\mathrm{AV}$ and Wimmer E (2012) Identification of two functionally redundant RNA elements in the coding sequence of poliovirus using computer-generated design Proc Natl Acad Sci USA 109 14301-14307

Tamura K, Peterson D, Peterson N, Stecher G, Nei M and Kumar S (2011) MEGA5: Molecular evolutionary genetics analysis using Maximum Likelihood, Evolutionary distance, and Maximum Parsimony methods Mol Biol Evol 28 2731-2739

Times of India (2013) Hand, foot, mouth disease spreads. Times City, Bangalore, August 7

Vijayaraghavan PM, Chandy S, Selvaraj K, Pulimood S and Abraham AM (2012) Virological investigation of hand, foot, and mouth disease in a tertiary care center in South India J Glob Infect Dis 4 153-161

Wang YF, Chou CT and Lei HY (2004) A mouse-adapted anterovirus 71 strain causes neurological disease in mice after oral infection $J$ Virol 78 7916-7924

World Health Report 2004 (2004) World Health Organization, Geneva, Switzerland

Western pacific Regional Office of the World health Organization. WPRO hand foot and mouth disease situation update [Internet] (2013). Acessed Dec 2014 at http:// www.wpro.who.int/emerging_diseases/HFMD. Report.8Jan2013.pdf.

Wu Y, Yeo A, Phoon MC, Tan EL, Poh CL, Quak S H and Chow VT (2010) The largest outbreak of hand, foot andmouth disease in Singapore in 2008: the role of enterovirus 71 andcoxsackievirus A strains Int J Infect Dis 14 e1076e1081

Xing W, Liao Q, Viboud C, Zhang J, Sun J, Wu JT, Chang Z, Liu F, Fang VJ, Zheng Y, Cowling BJ, Varma JK, Farrar JJ, Leung GM and Yu H (2014) Hand, foot, and mouth disease in China, 2008-12: an epidemiological study Lancet Infect Dis 14 308-318

Yamashita T, Sakae K, Ishihara T, Isomura S and Utagawa E (1993) Prevalence of newly isolated, cytoplasmic small round virus (Aichi strain) in Japan J Clin Microbiol 31 2938-2943

Yetterberg SR, Mahowald ML and Messner RP (1987) Coxsackievirus B1-induced polymyositis: lack of disease expression in nu/nu mice $J$ Clin Invest 80 499-506. 